Derecho y Realidad

Vol.13 - Núm. 26 • Julio-Diciembre de 2015

Pázs. 55-71.ISSN:1692-3936

\title{
Los jueces en la democracia del Estado constitucional*
}

\section{The judges in the democracy of the constitutional State}

\author{
Dídima Rico Chavarro**
}

\section{Resumen}

Este artículo se aproxima a la temática sobre el papel de los jueces en la democracia del Estado constitucional de derecho, a propósito de la importancia entre democracia y justicia de los jueces, que Gustavo Zagrebelski desarrolla como democracia dúctil, por cuanto remite la resolución de las decisiones difíciles a la ponderación entre principios a la justicia material, para contribuir al cuestionamiento y proscripción del concepto del derecho que él considera agotado en la obediencia a la ley.

\section{Palabras clave}

Justicia de los jueces, Democracia, Democracia dúctil.

Fecha de aceptación: 8 de agosto de 2015

Concepto de recepción: 27 de agosto de 2015

Fecha de aprobación: 15 de noviembre de 2015

* Artículo de reflexión producto del proyecto de investigación terminado: El papel de los jueces en la democracia constitucional, 2015, como investigadora de la UPTC.

** Doctora en Derechos Fundamentales, Universidad Carlos III de Madrid. Profesora investigadora Universidad Autónoma de Colombia. Profesora asistente medio tiempo. didima.rico@uptc.edu.co 


\section{Abstract}

This paper is an approach to the role of judges in the democracy of the constitutional State of law, with regard to the importance between democracy and justice of judges that Zagrebelski develops as ductile democracy, inasmuch as it forwards the resolution of the difficult decisions to the weighting between principles to material justice, in order to contribute to the questioning and prohibition of the concept of the law that he considers finished in obedience to the law.

\section{Keywords}

Justice judges, democracy, Ductil democracy.

\section{Sumario}

1. Las bases del estado constitucional de derecho

2. La democracia constitucional

3. La teoría democrática constitucional de Zagrebelsky

4. Desarrollo de los planteamientos de la interpretación práctica del derecho

5. Conclusiones y referencias

\section{Método}

Jurídico-hermenéutico de orden deductivo sobre análisis documental de orden teórico-práctico.

\section{Metodología}

La metodología hermenéutica se ha centrado en un procedimiento analíticoconceptual de orden deductivo, tomando como premisas las concepciones normativo-teóricas de las fuentes seleccionadas con miras a deducir los elementos relevantes desde las perspectivas epistemológicas que respondan a nuestra pregunta de investigación.

¿Cuál es la relación entre los las herramientas teóricas de la interpretación del derecho constitucional y el actual estado democrático?. 


\section{Introducción}

En este ensayo se analiza el papel de los jueces como garantes de los valores, principios y derechos que identifican la democracia constitucional, por la importancia de articular el horizonte político con teorías y métodos de interpretación constitucional que acentúan el protagonismo de la justicia material en el quehacer de los jueces en el Estado constitucional de derecho.

En la democracia constitucional, la efectividad de la justicia se evidencia en cada una de las decisiones con que los jueces expresan la majestad de la administración de justicia propia del Estado de derecho, como lo afirma el filósofo del derecho Gustavo Zagrebelsky, pero también porque hay un giro hacia un concepto material del Estado de derecho que, como lo afirma Ernest Bockenforde, se entiende vinculado a "determinados valores y principios superiores del derecho" y a establecer una "situación jurídica justa en sentido material" (2000, p. 40)

Cuando los jueces, al proferir sus providencias, se toman en serio su papel de garantes e intérpretes autorizados de la Constitución, se robustece la confianza y la credibilidad en la administración de justicia, el desarrollo del principio de independencia y autonomía judicial, que define la democracia como independencia entre las ramas del poder público.

El reconocimiento del respeto de la dignidad humana y la realización de los derechos fundamentales como conquistas históricas y sociales de la modernidad, producen espacialidades, relaciones in situ, que desarrollan estrategias locales para contener el poder del Estado, y nuevas formas sociales para la exigibilidad y garantía plena de los planes de existencia personales y colectivos de los sujetos de derechos.

Los paradigmas epistemológicos que van más allá de la tradición derecho-ley se pueden condensar en la famosa frase del juez norteamericano Oliver Holmes: "la vida del derecho no ha sido la lógica, ha sido la experiencia" (Arjona, 2006, p. 19), y ayudan a construir una nueva estructura constitucional de la democracia judicial, con destacados pensadores como Zagrebelsky, Fioravanti, Böckenförde, Bobbio, Ferrajoli. También, a manera de ejemplo, se cuenta con los aportes de Diego López, Rodrigo Uprimny, Mauricio García, entre otros, así como con los avances de la jurisprudencia progresista de la Corte Constitucional.

Como base de análisis del objeto de estudio se referencian algunas fuentes primarias y secundarias de autores, que pueden considerarse clásicos de la democracia constitucional. En la década de los 80 emerge el poder de los jueces constitucionales, 
cuyo ejercicio se centra en un conjunto de valores y principios caracterizados por el pluralismo, la solidaridad y la democracia participativa. EI protagonismo de los jueces responde a la visión del derecho, en alianza con la justicia, y en esa proyección se indaga por la relación entre derecho legal y derecho constitucional, como afirma Zagrabelsky (1996, p. 9).

La creación del derecho como institución de control social de los comportamientos humanos, tanto en lo privado como en lo público y frente a vínculos con la forma como se organiza la democracia, influye en la manera como se administra justicia, el papel de los jueces frente al concepto de justicia y la distancia del derecho equivalente a ley y el de justicia sometida a la ley o, como dice Bockenforde, legalidad de la administración y la garantía judicial que se constituyen en el contenido del Estado de derecho (2000, p. 30).

\section{Las bases del Estado constitucional de derecho}

Después de la Segunda Guerra Mundial y ante el temor y el acecho permanente de los tentáculos del totalitarismo, que en su vientre llevaba la expansión de la economía imperialista y de los instrumentos jurídicos puestos al servicio del régimen nazi, en nombre de la ley se impuso como legal el horror y la muerte de millones de personas por su raza, ideología o política, como los comunistas, los judíos, como lo denunció Hannah Arendt (2005).

La nueva visión de la importancia geoestratégica de los recursos naturales y territoriales, con aspiración de dominio y explotación hegemónica de los recursos del planeta, dejaron abierto el contexto para el establecimiento de los cimientos de una nueva visión del derecho y del Estado.

Con el nuevo orden jurídico internacional de corte occidental, se abrió la posibilidad de repensar las prácticas que, amparadas en un manto de legalidad -expresada socialmente como legitimidad, en cuanto consentida por mayorías sociales de un espacio territorial- correspondían al Estado de derecho de corte liberal tradicional.

El marco que definía el Estado de derecho-ley, según Ernest Böckenförde, es el "'Estado del derecho racional', el Estado que realiza los principios de la razón en y para la vida en común de los hombres, tal y como estos estaban formulados en la tradición de la teoría del derecho natural" (2000, p.19).

Frente al "Estado de la razón", que al calor de las guerras mundiales dejó al descubierto la irracionalidad de su aspiraciones como mecanismo de construcción de paz, la comunidad internacional después de la devastación que ocasionó la Segunda Guerra Mundial, acordó unos dispositivos jurídicos profundamente éticos, dirigidos 
a encausar los valores y principios centrados en el universalismo occidental, basado en las libertades individuales.

Los cimientos del nuevo orden jurídico internacional, dirigidos a mantener la paz y la seguridad internacional, para superar las causas de las dos guerras mundiales que afectaron el desarrollo de la humanidad en términos de violación de derechos humanos por parte de los Estados y la conexión entre ellos, se concentraron en dos ideas gruesas del nuevo pacto, el reconocimiento de la dignidad y los derechos fundamentales de la persona humana. Estas ideas se convirtieron en el núcleo de los ordenamientos jurídicos de los países miembros de la Organización de Naciones Unidas (ONU), creada en 1945, y se materializaron con la expedición de la Declaración Universal de Derechos Humanos (DUDH, 1948), reconocidos como la fuente normativa por excelencia del nuevo orden jurídico internacional (Ollé \& Acebal, 2009, p. 21).

La incorporación de la dignidad humana en las cartas fundamentales de los Estados nación otorgó al Estado de derecho un horizonte ético para la humanidad en su conjunto y definió los límites que el poder político debía tener en su ejercicio frente a las personas consideradas sujetos de derechos (Rico, 2009, p. 587).

Con ese propósito, se hizo necesario revisar el concepto de democracia, para vincularla con el derecho, el poder y los derechos fundamentales. Como consecuencia, sus calificativos sufrieron profundos cambios, que evidencian la transformación del concepto de derecho y sus implicaciones para la justicia y su administración.

\section{La democracia constitucional}

La renovación de las concepciones que comenzaron a relacionar la democracia con el derecho y los derechos humanos en el contexto del quehacer de la justicia, cuenta con Zagrabelsky entre los pensadores con aportes importantes para el desarrollo de las bases teóricas del Estado constitucional de derecho, con un margen de aproximación conceptual que pone al sujeto de derechos en el centro de la argumentación sobre la justicia.

A fin de identificar el concepto fundamental sobre el poder de los jueces en la democracia, nos referiremos a Zagrebelsky, quien en su obra El derecho dúctil, publicada en Italia por los años 80 , expone la transformación del derecho positivo, cerrado en torno a la soberanía de la ley y del principio de legalidad, propios de las democracias representativas que caracterizaron el siglo XIX para reivindicar una visión del derecho que diera cabida a los valores y la justicia, en el horizonte del derecho, asumido desde una visión naturalista. 
El nuevo modelo introducía principios propios de la posmodernidad, la pluralidad, la diversidad, la solidaridad, la justicia material, que como carta fundante de los Estados contemporáneos, recoge valores y principios de justicia material, como un sistema abierto a la interpretación de la ley, sometida a los valores superiores del ordenamiento jurídico político, la Constitución política.

En ese sentido, se introduce la separación de funciones entre poderes públicos, que se conjuga con el libre juego de actores plurales, de grupos heterogéneos, de múltiples ordenamientos, con márgenes constitutivos de pequeños centros que convergen hacia el centro, hacia el Estado (Böckenförde, 2000, p. 31).

Esa nueva conformación da al traste con la soberanía de la ley e impone como estrategia de las decisiones judiciales complejas, la ponderación por principios, las transacciones entre estos dispositivos programáticos en igualdad de condiciones y de oportunidades, sin más reglas formales que la optimización de los principios constitucionales. En ese sentido se consideran los aportes de Ronald Dworkin, con su teoría del derecho como integración, con lo cual se pone en el centro del debate sobre la filosofía del derecho el concepto del derecho de Hart.

En el Estado constitucional, las reglas de principio de carácter prevalente propenden la realización de las condiciones de posibilidad de la vida en dignidad y en la medida en que puedan ser contenidos de manera abierta en las constituciones, son los que permiten una dogmática jurídica, Ilamada "Iíquida o fluida" (Zagrabelsky, p. 17).

En ese horizonte emerge una teoría que socava las bases del positivismo jurídico duro, al que corresponde el legocentrismo de Kelsen, fuente del desconocimiento de principios y derechos fundamentales de los asociados. En países como Colombia, esa tradición contribuye a que jueces apegados a los atavismos del núcleo duro del positivismo jurídico, desconozcan los principios y derechos fundamentales de las personas como centro de los ordenamientos jurídicos.

En el derecho dúctil, Zagrebelsky toma distancia del positivismo jurídico como teoría del derecho y se aproxima a una visión del derecho de corte naturalista, anclado en la interdependencia entre derecho y moral, pues el Estado constitucional, como lo afirma Ricardo Guastini, responde a las siguientes tesis:

a) Los derechos subjetivos (inviolables) son completamente independientes de la ley; es más, son previos y supraordenados a la ley, y protegidos, porque encentran su fuente en la constitución B) los principios de justicia positivizados en la Constitución son igualmente independientes de la ley, previos y supraordenados a ésta, y por tanto inviolables para el legislador. (1996, p. 112) 
Sin embargo, en su disputa con el positivismo "formalista legicentrista" del positivismo tradicional, Zagrabelsky no reconoce que este fue corregido con la regla de reconocimiento, que Herbert Hart introduce con una visión empirista al operar o legitimarse en las prácticas sociales aplicadas al caso que se va decidir, "como remedio a la falta de certeza del régimen de las reglas primarias", que corresponde a una regla del grupo, sustentada por la presión social que este ejerce en el concepto del derecho, por la observación de la regla de reconocimiento que se fundamenta en unos parámetros de justicia material, en cuanto acude a las prácticas sociales que son tenidas en cuenta por el juez al decidir un caso difícil (1963, p.117) y en una estrecha relación entre poder político, constituyente primario, justicia y derecho, como lo explicita Norberto Bobbio, en la medida en que el "derecho delimita y disciplina la acción política".

La diversidad de decisiones propias de la discrecionalidad que Herbert Hart introduce en el concepto del derecho, a propósito de los casos límite discutibles (1963, p. 5), son cuestionadas por Ronald Dworkin en su obra Los derechos en serio, al afirmar que en las decisiones judiciales, los jueces solo pueden dar una respuesta correcta cuando se presenta un caso difícil, porque la respuesta solo puede tener como fundamento las cuestiones de principio que según el derecho como integridad, constituyen el derecho constitucional que administra (2005, p. 267).

La controversia entre Hart y Dworkin, entre positivismo y iusnaturalismo, fue una de las disputas teóricas más interesantes que atravesaron la filosofía del derecho de la segunda mitad del siglo XX, a propósito de las decisiones judiciales y del poder judicial al aplicar el derecho. Disputa que fue clasificada como la tensión entre dos teorías, positivismo e iusnaturalismo, que por tener sus raíces en las distintas visiones de la filosofía política con las que emerge el derecho en la modernidad, no ha sido posible a partir de los fundamentos Ilegar a acuerdos, de ahí que el conflicto se dirimió por el método de aplicación que cada una de ellas asume, como queda argumentado en el estudio preliminar de César González, a propósito del texto El debate Hart y Dworkin.

Es posible garantizar una mejor convivencia social a partir del respeto a los principios, sin desconocer que esta tampoco agota la solución correcta a los problemas jurídicos, los cuales se reducirían y serían mas fáciles si las políticas constitucionales y los ordenamientos jurídicos garantizaran por parte del Estado la prestación de los derechos sociales, económicos y culturales de los asociados y se propendiera a una distribución de los recursos mas equitativa para todos los ciudadanos, permitiendo el libre juego y desarrollo de los derechos individuales, con las limitaciones que a estos le imponen los derechos de justicia. 
En este punto es interesante y de vital importancia el planteamiento de Zagrebelsky, aunque a veces parece cruzarse la línea que define los principios constitucionales con problemas de justicia, en los que no se ha detenido este estudio, por tener otros propósitos, dada la complejidad y especialización de la materia tratada.

\section{La teoría democrática constitucional de Zagrebelsky}

Para Zagrebelsky, el Estado actual se asume a través del constitucionalismo que se caracteriza por lo siguiente:

- En las declaraciones constitucionales de derechos, además de la diversidad de contenido y estructura explicable por los ideales políticos históricos, subyace una distinción fundamental relacionada con el ethos de los derechos, los que vincula a dos tradiciones: la libertad (humanismo laico) y la justicia (humanismo cristiano), la violación de los derechos de la primera quebranta la pretensión de libertad, la violación de los derechos de la segunda vulnera la pretensión de la justicia (Zagrebelsky, 1995, p. 76).

- Esas profundas diferencias marcan la naturaleza misma de los derechos: Ios derechos de libertad se basan en la voluntad individual, son instrumentos para la realización de intereses particulares y por particulares, son de naturaleza meramente subjetiva. Los derechos de justicia, en cambio, son de naturaleza objetiva, tienden a reconducir la voluntad del ser humano al orden justo, como un deber de los que poseen más a favor de los que no poseen (Zagrebelsky, 1995, p. 85).

- La fijación en normas constitucionales de principios de justicia material destinados a informar todo el ordenamiento jurídico, son pautas que se inscriben en las constituciones como principios que definirán el horizonte que pretenden seguir los estados de derecho.

Entre las consecuencias, para superar el estado legislativo y la estructura de las normas jurídicas, Zagrebelsky (1995) manifiesta que el derecho es un orden objetivo previsto para limitar la inestabilidad de las voluntades, y que se compone de reglas y principios.

Las normas legislativas son prevalentemente reglas, mientras que las normas constitucionales sobre derechos y sobre justicia son predominantemente principios, a diferencia del Estado legislativo en el que las reglas supeditaban a los principios y estos para su aplicación dependían de ellas y estos solo eran tenidos en cuenta para el caso de algunas en las leyes. En ese punto, se puede apreciar un desarrollo similar al enfoque de Dworkin. 
Al distinguir principios de reglas, el autor diferencia Constitución de ley, a su vez reconoce que la Constitución también contiene reglas. Para él, solo los "principios" cumplen un papel constitutivo dentro del orden jurídico, las reglas se agotan en sí mismas, no tienen ninguna fuerza constitutiva, pues son manifestación expresa del orden jurídico (Zagrebelsky, 1995, p.110).

El derecho por principios abre paso a la formación de un derecho más flexible, más dúctil, como él lo llama, en el cual las reglas jurídicas se adecúan al caso (y no este a las normas como en el derecho legislativo) conforme a principios constitucionales y valores que se establecen en las constituciones, que acogen un pluralismo político e ideológico propio de las democracias. Este principio implica una amplia participación social sectorial con sus propios intereses, sus propias necesidades, con reglas concretas y temporales y no leyes generales y abstractas, que son la característica fundamental del Estado de derecho decimonónico. En ese contexto, el autor plantea la superación del positivismo jurídico por una interpretación más amplia del derecho, una interpretación a partir de la sociología jurídica del derecho, que obliga al juez a retornar a la realidad y operar a partir de la práctica.

\section{Desarrollo de los planteamientos de la interpretación práctica del derecho}

La teoría del autor es un aporte a las denominadas ciencias prácticas, a los métodos de interpretación del derecho, desde las teorías de discusión racional, a la razón práctica, para dejar de lado la lógica formal en la aplicación e interpretación de la norma y dar paso a la argumentación en la aplicación e interpretación a partir del discurso.

En ese propósito, Zagrebelzky desarrolla la necesidad de establecer procedimientos racionales a partir del caso, que toma como punto de referencia de su propia lógica, un supuesto de hecho que mediado por los principios permite adecuar la norma al caso y no como en el estado de derecho ley, en el cual, toda la aplicación e interpretación del juez se reducía a la ley. Su teoría no encaja adecuadamente en las teorías de la argumentación jurídica de las que Alexi y Habermas son sus máximos exponentes, porque aún no contienen las reglas deliberativas, reglas para seguir un procedimiento discursivo racional.

La ciencia del derecho positivo en un ordenamiento jurídico "por principios", debe considerarse una "ciencia práctica", porque del ser iluminado por los principios nace el deber ser. Las ciencias prácticas conducen el actuar y por tanto, la voluntad, que lo mueven al dominio de la razón. Su presupuesto es que la reflexión racional tenga algo que decir sobre la orientación de la acción. Esto es lo que se denomina "razón práctica" (Zagrebelsky, 1995, p. 121). 
En el Estado constitucional, según esta teoría, se pretende verificar que todos los poderes públicos se encuentran en igualdad de condiciones, sin que prime una soberanía de un poder sobre el otro, por el contrario emerge la fuerza de la separación y su correlato la independencia, que son los bastiones que legitiman las actuaciones u operaciones, en este caso del poder judicial.

Zagrabelsky identifica un criterio correcto para el buen vivir dentro de las sociedades pluralistas que caracterizan a las sociedades contemporáneas, heterogéneas, diversas, que para alcanzar ese fin, requieren de unos principios, de unos valores, que permitan estrategias que contribuyan a la multiplicidad de métodos. Pero esos dispositivos tampoco se agotan en una regla jurídica, sino que a esta se llega desde las condiciones y pretensiones propias que impone el caso.

La superación del Estado de derecho legislativo, con sus consecuentes separaciones entre ley, derechos y justicia, permite ver con claridad la nueva estructura de las normas jurídicas.

Por otra parte, la obra plantea soluciones a los grandes problemas jurídicos, que considera no están en las constituciones, en las leyes, en las decisiones de los jueces o en otras manifestaciones, sino en la idea que se tenga del derecho, de la Constitución, de la ley, la cual si realmente posee vida propia, incluso llega hasta desatarse de la < cosa > misma, y cita como ejemplo al Estado de Gran Bretaña.

El autor (1995, p. 18) manifiesta que hay que cuestionar la los < juristas inflexibles y sin matices $>$ aquello que se esconde detrás del derecho de los textos oficiales, es decir, de las ideas generales, los métodos, la mentalidad, las estructuras de pensamiento y los estilos jurídicos heredados del pasado que no encuentran justificación en el presente. El derecho dúctil se introduce en la práctica del derecho, desde el derecho positivo hacia una visión de sociología jurídica, de un sistema del derecho cerrado a un derecho flexible.

Las posiciones de Zagrebelsky en torno al derecho por principios, como razón práctica, enmarcan el contexto de la obra dentro de las discusiones que se presentan en torno al debate sobre la razón práctica y el derecho.

Zagrebelsky se aparta de la teoría de la argumentación jurídica expuesta por Robert Alexi, sus postulados no encajan en los de aquella, más bien, su teoría se ubica en uno de los modelos argumentativos de interpretación alternativa que este cita: el modelo hermenéutico, que según Robert Alexi, al afectar la relación norma-hechos, "despierta la mirada al problema de la contribución productiva del intérprete a la interpretación, lo que posibilita y estimula un comportamiento crítico. De allí, que al 
círculo del preentendimiento corresponde el postulado de reflexibilidad, que para la teoría de la argumentación jurídica es de gran significación", sus postulados de flexibilidad o de completitud son un aporte importante para la argumentación jurídica.

La interpretación práctica del derecho desde el modelo del círculo hermenéutico, como él mismo lo explica, se desplegaría de la siguiente manera:

En el proceso de interpretación del derecho, el caso es el motor que impulsa al intérprete y marca la dirección. Partiendo del caso se acude al derecho para interrogarlo y obtener de él una respuesta. A partir del caso, él interprete procede a buscar las reglas y regresa, en un procedimiento circular (el Ilamado "círculo interpretativo") de dirección bipolar que finaliza cuando se componen de modo satisfactorio las exigencias del caso y las pretensiones de las reglas jurídicas. (Zagrebelsky, 1995, p. 134).

Décadas después, el autor reafirma su tesis y la proyecta desde su posición de juez constitucional al señalar que la Corte es por esencia política, sin adscribirse a la política, se relaciona frecuentemente con la democracia, sin depender de ella, pues su misión fundamental es ser la salvaguarda de la Constitución.

El juez en sus decisiones expresa el mandato del constituyente primario en toda su diversidad y es el símbolo de la cultura de los pueblos que la erigieron como el cuerpo que orienta su destino político, por tanto, no toma partido con los ideales de un partido político, sino conforme a la función que le corresponde aplicar la carta política en el horizonte que ella fija al juez.

El problema de la interpretación que en principio propone el constitucionalista, es que lo correcto tiene muchas variables, diversos caminos por seguir, según la concepción del intérprete, o de la preconcepción que asume para adecuar la norma a partir del caso. La interpretación que se aplica en este modelo es un problema de argumentación, la razonabilidad compete al intérprete y la prudencia para que el derecho de principios cumpla su cometido, con lo cual el ordenamiento jurídico, como Zagrebelski lo afirma pierde certeza y fijeza jurídica.

En la teoría de Zagrebelsky puede decirse que el juez adquiere un poder bastante amplio, que Ileva la interpretación al Ilamado "señorío del juez" del que trata de huir por los problemas que entraña garantizar la justicia en su sentido material, dada las contingencias propias de los hechos de los casos.

De todas maneras, ese círculo interpretativo, al permitir una alta dosis de flexibilidad en manos del intérprete, puede en un momento dado llevar la interpretación a 
extremos subjetivos propios del intérprete, mediado por intereses particulares o por su posición política.

Dadas las tendencias pluralistas y concretas de las leyes que el autor (Zagrebelsky, 1995) afirma, actualmente se mantienen, además porque no puede existir una ciencia sobre la articulación de principios y jerarquía formal entre ellos, sino simplemente una prudencia en la ponderación entre iguales, más en la forma que en el contenido y en el caso al que se van aplicar.

Planteamientos que dejan muy abierto el campo al intérprete, lo cual puede conducir a la continuación de la fragmentación del derecho de la jurisprudencia, de la misma doctrina, y por ende como consecuencia su no sistematicidad puede conducir a un caos jurídico, a una incompatibilidad de argumentos entre poderes y a una inseguridad jurídica, por tanto, se puede poner en peligro la confianza en el propio Estado constitucional.

Sus planteamientos son de gran utilidad para el desarrollo, de la ciencia práctica, ese modelo

sin duda ofrece importantes juicios acerca de la estructura de la argumentación jurídica y encierra los tres fundamentales postulados de racionalidad mencionados, pero no es suficiente para la interpretación del problema de la interpretación correcta. La interpretación sólo puede justificarse cuando se aducen razones a su favor y en su contra de manera racional. (Zagrebelsky, 1995)

Por tanto, es más deseable la teoría del discurso, formulada por Robert Alexi, que a fin de evitar los problemas que se pueden deducir del modelo propuesto por Zagrebelsky, su solución se aproxima más a la interpretación correcta, al pretender entronizar una teoría del sistema jurídico con la teoría del discurso práctico, al aplicar al discurso y la argumentación, reglas que se refieren a la estructura de los argumentos y reglas cuyo objeto directo es el proceso del discurso, estas últimas con el fin de asegurar la imparcialidad de la argumentación práctica, con las cuales se pretende lograr el respeto del derecho de todos a participar con igualdad y libertad en el discurso, principio básico del Estado constitucional y democrático de derecho.

Por tanto, solo se justifican en la razón práctica los sistemas jurídicos que respeten las garantías de sociedades pluralistas. Es necesario que el procedimiento sea discursivo y "persuasivo", a fin de alcanzar el punto de máxima realización de los principios en juego, seleccionando una "clase jurídica" capaz de representar 
principios y no solo desnudos intereses o meras técnicas, condiciones necesarias para el triunfo de la prudencia en el derecho (Zagrebelsky, 1995, p.123).

Para Zagrebelsky, las reglas prevalentes son los principios constitucionales de justicia material, de carácter abierto y pluralista, que los únicos que fundamentan al Estado constitucional, de por sí, denota una diferencia en la fundamentación, porque ya no se parte únicamente de los derechos individuales, sino de los principios de justicia material, que él considera son de carácter social e imponen no solo derechos sino también deberes, pero estos argumentos de principio, que son prevalentes en Zagrebelsky, para Alexi, si bien cumplen el carácter de preceptos de optimización, son solo uno de los elementos de los argumentos sistemáticos que apoyan la idea de unidad o coherencia del sistema jurídico, junto a otros subgrupos de argumentos que este último desarrolla en su monumental obra.

El filósofo del derecho Zagrebelski propone que los jueces solamente deben anular una ley por inconstitucionalidad, cuando no se ajuste a las exigencias del caso, pero lo cierto es que las mismas reglas de interpretación que se le propone, con la pluralidad de métodos de principios y de valores abiertos, puede conducir a una supervaloración de sus funciones e indirectamente a legislar a través de la interpretación.

La pluralidad de principios y la ausencia de una jerarquía formal entre ellos, no es suficiente para suplir la posible falta de articulación en una ciencia y mucho menos que esta se logre solamente con la "prudencia en la ponderación" de los principios, es más posible lograrlo con la realización de la razón practica, a través de la "tensión entre autoridad y corrección del contenido". En Zagrebelsky el conjunto de los principios constitucionales debería constituir el "sentido común" del derecho.

Es necesario y preferible para la convivencia pacífica de la sociedad y para la resolución de conflictos, la existencia de ordenamientos jurídicos formales, con más reglas de argumentación generales y prácticas de carácter general y abstracto que permitan una mayor cobertura y una seguridad jurídica para el Estado.

Es importante reconocer que el principio de legalidad basado en la supremacía de la ley debe ser renovado o transformado en otro que guarde el respeto fundamental y primario de los principios y los derechos fundamentales, por sí mismos y por encima de la ley, la cual debe ser aplicada bajo la premisa de respetar en principio las reglas constitucionales, prevalentes, como la regla de convencionalidad propia de los Estados suscriptores de la Convención Americana de Derechos. En ese sentido, puede afirmarse con Ferrajoli, que el principio de legalidad no se queda en el de estricta legalidad, cuyo principio de la reserva de ley es propio del legislador 
para decidir qué es o qué no es delito, sino que también comprende el de "mera legalidad", dirigido a los jueces, quienes deben verificar y comprobar la desviación normativa, al decidir racional y razonablemente (Ferrajoli, 1997, p.35).

La dúctil coexistencia entre ley, derechos y justicia, cuyo garante es el juez, debe estar mediada por la observancia de un sistema jurídico articulado, en torno, no solo a principios abiertos, sino a la realización material de los mismos y la interpretación de la realidad, desde el punto de vista sociológico y del respeto de reglas de procedimiento que, a su vez, respeten las exigencias de la razón práctica.

La interpretación jurídica propuesta por Zagrabelsk se concibe como un discurso racional, en la medida que el intérprete del derecho conjuga dentro de su ejercicio categorías que asumen la realidad viviente, que parten del hecho (del caso) y se despliega en busca de la norma acorde al caso concreto y al ordenamiento. Se entabla una relación directa entre norma por aplicar, caso y ordenamiento jurídico, y lograda esa relación, se tiene la solución adecuada al caso, o la solución correcta.

El sentido de la interpretación judicial se propone una mirada dinámica de las reglas y principios que conforman las unidades temáticas del ordenamiento jurídico, por ello, su estudio se centra en el derecho, su aplicación, no solo tratando de reconstruir los argumentos presentados en las sentencias por los jueces, sino también, como los razonamientos que a través de argumentos se presentan por los usos que realizan los operadores jurídicos que actúan ante esos jueces, donde se transforman, modifican, adecúan e incluso se distorsionan.

De ahí, que la reflexión sobre el papel que juega la interpretación judicial en la compresión y vida del derecho, tiene entre sus propósitos fundamentales: i) adquirir herramientas para aproximarse al quehacer de los abogados, los jueces, los funcionarios o los ciudada-nos, en general, cuando dicen estar "cumplien-do", "aplicando" o "argumentando" en derecho, y ii) desarrollar destrezas y habilidades básicas para presentar argumentos con enfoques de interpretación en cualquiera de los roles que cumplen como abogados.

En el ordenamiento no se puede considerar que haya una sola solución correcta para el caso, porque sería considerar el ordenamiento de manera cerrada, por el contrario, en ocasiones hay casos críticos que permiten varias adecuaciones a varias normas y valores del ordenamiento.

La aplicación de la ley en el Estado decimonónico, partía y terminaba en la interpretación de la misma ley, el caso debía someterse a las exigencias de la ley, sin importar sus propias condiciones, pues regía el principio "dura lex sed lex", 
quintaesencia del positivismo acrítico. En el derecho de interpretación práctica, el intérprete parte del caso, a partir de la situación busca la regla y regresa al caso, una metodología que sigue un procedimiento circular.

Las exigencias y condiciones de los casos cuentan más que la voluntad legislativa, pudiendo incluso, llegar a invalidarla. El juez debe, entonces, elegir entre sacrificar las condiciones del caso o las de la ley, son estas últimas las que sucumben en el juicio de constitucionalidad al que la misma ley viene sometida.

El caso es un acontecimiento problemático que exige solución. Adecuar la regla al caso, a la comprensión del caso, lo cual presupone que se entiendan adecuadamente sentido y validez. Sentido como conexión entre acción y resultado social, solo se alcanza sentido si se la pone en relación con los efectos que puede producir, mientras que la validez, de alguna manera se liga a su existencia, pero se asume como aspecto normativo, que contiene procedimientos que se deben cumplir.

La comprensión del sentido determina la comprensión del valor de cara al juicio. La categorización de sentido y valor permite la solución adecuada del caso. Todas las manifestaciones jurídicas (en un ordenamiento constitucional) del caso afectan tanto a quien crea como a quien interpreta el derecho.

El derecho no puede separase del ambiente cultural en que se halla inmerso y erigirse como sistema normativo independiente y autosuficiente, es una parte del todo que depende y se entroniza con el caso, que en ocasiones presiona para que se reforme, o se plantea una cuestión de inconstitucionalidad. De ahí que, como afirma Gustavo Zagrebelsky, la flexibilidad o ductilidad de la "interpretación constitucional, contribuya a la capacidad de adaptación de las constituciones, transformando sin reformas explicitas nuevas condiciones históricas" (2014, p. 227).

El autor continúa afirmando que "el principio no encierra la solución", así el derecho "por principios" muestra su dimensión concreta y la ineludible Ilamada que contiene a la prudencia de quien debe hacerlo vivir (Zagrebelsky, 2007, p.144).

Para terminar, Zagrebelsky afirma que el derecho por principios conlleva

el reconocimiento de los derechos de los individuos, pero también los derechos de la sociedad; la valoración de las capacidades espirituales de los individuos, pero también la protección de los bienes colectivos frente a la fuerza destructora de aquellos; el rigor en la aplicación de la ley pero también la solidaridad ante sus consecuencias más rígidas, la responsabilidad individual en la determinación de la propia existencia, pero también la intervención colectiva para el apoyo de los más débiles (1995). 
En ese contexto, no solo los principios y valores abiertos deben ser las reglas jurídicas, es importante que las leyes entren en juego, como reglas, siempre y cuando respeten antes que la legalidad los derechos fundamentales de los seres humanos, sin cuyo respeto es imposible la realización de sociedades que logren el buen vivir, la convivencia pacífica y la distribución equitativa de recursos materiales

\section{Conclusiones}

Los planteamientos teóricos sobre el Estado constitucional y la interpretación son de gran importancia para la ciencia constitucional y para la discusión de las teorías sobre derecho y razón práctica: las teorías de la argumentación, por ejemplo de Zagrebelsky, abarcan temas del derecho constitucional, desde la descripción de las características del Estado constitucional, su justificación y su desarrollo general.

Su análisis comprende el campo de la aplicación e interpretación del derecho a través de su propuesta de argumentar racionalmente, teniendo en cuenta que los principios constitucionales materiales son "el sentido común del derecho", los que fijan las pautas para resolver los casos, los grandes problemas jurídicos del derecho actual, considerando la heterogeneidad de sectores sociales y de la ley, los intereses particulares que consagran las leyes actuales, la desintegración de la dogmática cerrada del positivismo jurídico y de la supremacía de la ley.

Resulta relevante ir a los autores clásicos del derecho constitucional y a la razón de ser de los jueces para dialogar con ellos y retomar los fundamentos de la justicia material, desde distintas visiones que nos indican que el problema ideológico persiste y que, aunque los métodos si bien ayudan a dar soluciones, no se puede perder de vista desde donde se construye, desde donde se hace y cómo se hace derecho. La relación entre justicia material y derecho sigue en el contexto que define el derecho y que lo vincula con la razón de ser de los Estados constitucionales, como bien lo ratifican Ferrajoli y Alexi, entre otros.

\section{Referencias}

Alexi, R. (1995). Teoría del discurso y derechos humanos. L. Villar (trad.). Bogotá: Universidad Externado de Colombia.

Arjona Sebastia Cesar. 2006, "Los votos discrepantes del juez O.W.Holmes" Estudio preliminar y traducción de cesar Arjona Sebastia. Madrid, Lustel- 
Arnaud, A.J. \& Fariñas, M. J. (1996). Sistemas jurídicos, elementos para un análisis sociológico. Madrid: Universidad Carlos III.

Bobbio, N. (2009). El futuro de la democracia. México: Fondo de Cultura Económica.

Bockenforde, E. W. (2000). Estudios sobre el Estado de derecho y la democracia. Madrid: Trotta.

Dworkin, R. (2005). El imperio de la justicia. De la teoría general del derecho, de las decisiones e interpretaciones. De los jueces y de la integridad política y legal como clave de la teoría y práctica. Barcelona: Gedisa.

Ferrajoi, L. (1995). Derecho y razón. Teoría del garantismo penal. Madrid: Trotta.

García, J. A. (1995). La filosofía del derecho de Habermas y Luhman. Bogotá: Universidad Externado de Colombia.

Harendt. Hannah. Los orígenes del Totalitarismo, Madrdi, alianza editorial, 2006.

Hart, H. (1963). El concepto de derecho. Buenos Aires: Abelledo-Perrot.

Guastini, R. (1996). Dialnet. Anuario de Filosofía del Derecho, 13, 111-123.

Habermas, J. (1998). Facticidad y validez. M. Jiménez (trad.). Madrid: Trotta.

Rico, D. (2010). Aportes conceptuales para una redefinición de la idea de dignidad más allá de lo racional. En Problemas de la filosofía del derecho, la política y la argumentación jurídica en Colombia (pp. 749-757), Bogotá: Universidad Libre.

Zagrebelsky, G. (1995). El derecho dúctil. M. Gascón (trad.). Madrid: Trotta.

Zagrebelsky, G. (2008). Principios y votos. El tribunal constitucional y la política. M. Martínez (trad.). Madrid: Trotta.

Zagrebelsky, G. (2014). La ley su justicia. Tres capítulos de justicia constitucional. Madrid: Trotta. 